\title{
Affective relationships between users and libraries in times of economic stress
}

\author{
Angeliki Giannopoulou, Giannis Tsakonas \\ Library \& Information Center, University of Patras, \\ 26504, Rio, Patras, Greece \\ agianop@upatras.gr,gtsak@upatras.gr
}

\begin{abstract}
Academic libraries are considered as key factors in the educational system of a country and strong pylons for the economic and societal development. During the current economic recession, libraries have been struck by severe budget cuts that have forced them to shrink and to reconsider services to the end users. Important questions that have been raised in countries, such as Greece, which has been in the eye storm of the economic downturn and has witnessed severe societal changes, include how libraries respond to this change of conditions, how they improve their service level and how they minimize user dissatisfaction. Moreover, one of the key questions is what is the range of substantial or symbolic interventions that can improve users' affective relationship with the libraries? The study aimed to measure the opinion of academic libraries users on four main criteria categories, namely cost, space and atmosphere, personnel behavior, and facilitation of collaborative work, and to reflect the level of affective relationship of users with their libraries. The study provides representative findings from all Greek academic libraries and shows that libraries are considered as spaces that facilitate pleasant reading and studying, as well as efficient collaborative work. Library users are in overall satisfied by the personnel behavior and productivity, but they also believe that there are margins for further improvement of its knowledge, while they think that the cost of services should be revised and echo the current situation. The findings of the study can assist library administrators to define the range of interventions and to prioritize them in a period of limited resources.
\end{abstract}

Keywords: Greek academic libraries, user satisfaction, service quality, service evaluation.

\section{Introduction}

Since 2008 the entire world is in a whirlwind of economic insecurity. Some countries had had problems, but they went over them, but other are in a long period of recession that has severely affected their population. Greece is one of these countries that has been gone under a major plan of fiscal adjustment, mainly translated into austerity measures. Recent statistics show that the average income has been decreased by $50 \%$ and that the official unemployment rate is $27 \%$ of the population, while the Hellenic Statistics Authority announced that the recession rate in 2013 - the sixth year in a row - will be between 4 and $4.5 \%$ of the GDP. This is an important hit to the economic activity and the daily life of the citizens, while its effects run through the entire backbone of the Greek society. This situation is reflected in all the educational structure of the country, which also goes under a major reshape. Consequently these 
effects reach the Greek libraries in the form of big budget cuts, personnel firing, ${ }^{1}$ and so on. It can be estimated that after a twenty years of growth and development, Greek libraries have returned to the state before 1990 that they "were hardly able to operate due to scarce funding and resources that were not directed to these institutions" [Kyrillidou, 2006].

The aim of this study is to identify the critical parameters that govern the affective relationships between academic libraries and their users. We mainly study the feelings of the library users and we argue that it is important to define those parameters especially inside this asphyxiating context the Greek academic libraries are in, because we think that there hardly is a challenging setting like this in the Western world. In this study we have used the Stimulus - Organism - Response (S.O.R.) framework to identify these parameters and this is the first time that it has been implemented in the Greek academic libraries. The survey followed a quota sampling technique and was addressed to users of all levels (undergraduate and post-graduate students, faculty members, etc.) from all academic libraries across Greece, resulting in 950 questionnaires that were then processed with inferential statistical methods.

\section{Background}

Library assessment is considered to be the set of processes to assign value to a given unit on a given time point. Wright and White [2007] prologuing the ARL Library Assessment toolkit state that the "number of assessment activities undertaken in libraries over the last decade has grown exponentially". While this echoes the practices of US libraries at that given time, the same can be said for most parts of the world. But, library assessment researchers understand the importance of standardized measurement activities that can be unambiguous and comparable over similar units or over time. This eventually leads to system-centered and -based statistics, such as web usage, books loan, fees, library visits and so on. In contrast, the user-centered and based evaluations are prone to the context of enquiry and might not be easily interpretable by other bodies. Occasionally, the tools of measurement reflect something very specific and individualistic, which can not be later reused.

In Greece, there are a few nation-wide systematic surveys, mainly between formal bodies, that cover the first leg of studies. The Total Quality Management Unit $(\mathrm{MOPAB})^{2}$ is the body that annually collects academic libraries' statistics. MOPAB focuses on collections growth, personnel figures, library usage and book price rates. Similarly, the Hellenic Statistical Authority biannually collects data in similar fields. On the other side, one can find plenty of user-based studies over the last years that are either very limited in scope, or due to methodological propositions they can not support generalization of their results.

\section{Motivation}

In this study we aimed at finding a consistent way of measuring the users' emotions inside the physical place they act, especially during challenging times. As it has been

\footnotetext{
${ }^{1}$ Approximately 100 librarians from the academic libraries of the eight larger Universities were dispossessed of their positions in September 2013

${ }^{2} \mathrm{http}: / /$ www.mopab.gr
} 
mentioned much of the work in library evaluation research up to now has been focused on users' satisfaction, preferences and service evaluation, but not on feelings. By feelings we mean the emotional states in which the library users find themselves while using the library services. Obviously, these can be either positive, or negative and we argue that the affective relationships can shape a respective user experience in the library. Of course the feelings' effects are reinforced in times of stress, as it has been recollected by our Library's personnel. Library users in Greece work in difficult conditions and they often seek for security, understanding, comfort and warmness. Furthermore they seek for motivational spaces that will make them feel confident and excited and that they will be received by a willing personnel. During this period, State organizations, such as libraries, despite they have been criticized for their performance, are shielding vulnerable classes of users, like low income students. Powell [2006] mentions ten reasons why libraries evaluate their collections and services, listing (i) account for how they use their limited resources, (ii) explain what they do, (iii) enhance their visibility, (iv) describe their impact, (v) increase efficiency, (vi) avoid errors, (vii) support planning activities, (viii) express concern for their public, (ix) support decision making and (x) strengthen their political position. Some of the reasons correspond to system centered and based evaluation approaches, but in the case of our research the last three are the main reasons for libraries to engage in such studies.

\section{Methodology}

One of the most important methods of evaluating the quality of library services is the survey method. A well structured questionnaire was used for the data collection process. Participants were users of all Greek Academic Libraries (21 libraries), except the University of Peloponnese. ${ }^{3}$ Quota sampling (non probability sampling method) was used for selecting participants. Sample quotas for each Greek Academic library were proportionate to the total number of the population of users in each Greek Academic Library (see Table 2). This ensures that the final sample of the study is representative to the population in terms of number of users of Greek Academic Libraries.

The survey's questionnaire included Likert type questions regarding: (i) the level of knowledge and usage of services provided by the Greek academic libraries, (ii) the evaluation of these services according to user perceptions, (iii) the three dimensions proposed by the LibQUAL model (information control, affect of service and library as place) and (iv) participant's demographics. A pilot study to check the reliability of the items of the constructs (and the conceptualization and operationalization of questionnaire construction) took place at the Library \& Information Center of University of Patras. Reliability test Cronbach $a$ was found to be good with $a>0.7$ for all constructs.

\footnotetext{
${ }^{3}$ The statistical database of MOPAB had no library user data available for University of Peloponnese, so we could not calculate the corresponding sampling quota (research limitation).
} 
Table 1: Sampling quotas per Greek academic library

\begin{tabular}{|c|c|c|c|}
\hline Library name & Library users & $\begin{array}{c}\text { Library users } \\
\text { /total population }\end{array}$ & $\begin{array}{c}\text { Sample size } \\
\text { needed by each } \\
\text { library }\end{array}$ \\
\hline Athens School of Fine Arts & 1,600 & 0.00631 & 6 \\
\hline Aristotle University of Thessaloniki & 41,930 & 0.16541 & 165 \\
\hline Agricultural University of Athens & 4,229 & 0.01668 & 17 \\
\hline Democritus University of Thrace & 12,390 & 0.04887 & 49 \\
\hline International Hellenic University & 470 & 0.00185 & 2 \\
\hline National \& Kapodistrian University of Athens & 11,169 & 0.04406 & 44 \\
\hline National Technical University of Athens & 15,149 & 0.05976 & 60 \\
\hline Ionian University & 5,433 & 0.02143 & 21 \\
\hline Athens University of Economics \& Business & 12,903 & 0.05090 & 51 \\
\hline University of the Aegean & 9,943 & 0.03922 & 39 \\
\hline University of West Macedonia & 3,000 & 0.01183 & 12 \\
\hline University of Thessaly & 20,677 & 0.08157 & 31 \\
\hline University of Ioannina & 12,699 & 0.05009 & 50 \\
\hline University of Crete & 16,237 & 0.06405 & 65 \\
\hline University of Macedonia & 10,797 & 0.04259 & 42 \\
\hline University of Patras & 25,033 & 0.09875 & 99 \\
\hline University of Piraeus & 22,808 & 0.08997 & 90 \\
\hline University of Central Greece & 312 & 0.00123 & 2 \\
\hline Panteion University & 18,014 & 0.07106 & 71 \\
\hline Techical University of Crete & 6,958 & 0.02744 & 27 \\
\hline Harokopeio University & 1,734 & 0.00684 & 7 \\
\hline TOTAL & 253.485 & & 950 \\
\hline
\end{tabular}

After communicating with all Library Directors, the data collection process initiated by sending the appropriate number of questionnaires (according to quota sampling) to the 21 Greek Academic Libraries. The data collection period was between April and July 2012.

\section{SOR framework}

The Stimulus - Organism - Response (S.O.R.) framework is a model for the exploration of customer behavior. It has been proposed by Mehrabian and Russell [1974] in pursue of establishing the link between physical environment and 
individual's behavior. The model empowers the customer to act as a catalyst that processes environmental stimuli to effects, emotional and/or cognitive. In our study we focus in the emotional effects. The model has been also used for predictive purposes, taking benefit of the sequential characteristics [Kim \& Lennon, 2012]. In this setting, S.O.R. has been used for exploratory purposes; to model and interpret the critical variables that shape the affective relationships between users and libraries.

This section introduces the S.O.R. model and each of its dimensions from the perspective of retail store environment. The environmental psychology literature asserts that the physical environment influences the approach-avoidance behavior of individuals within it [Mehrabian and Russell 1974]. S.O.R. describes mechanisms for how environmental elements influence individuals' internal states and in turn their approach-avoidance behaviors. They propose that emotional states serve as mediating variables in determining a variety of approach-avoidance behaviors. Following the S.O.R. model, a number of marketing studies on atmospherics generally support the relationship between store environment and consumer behavior [Baker,1987]. In a retailing context, the atmospheric variables are the stimuli $(\mathrm{S})$ that drive consumer evaluations $(\mathrm{O})$ and then influence their behavioral responses $(\mathrm{R})$. Consumer behavior responses within a retail store are either approach, or avoidance. This view is consistent with Markin, Lillis and Narayana's argument [1976] that retail store designers, planners, and merchandisers shape a retailing space, that creates one's mood, activates intentions, and affects a customer's reactions. On the basis of S.O.R. framework, environmental stimulus cues are the antecedents of consumer evaluations towards a retail store. Baker [1987] classifies environmental components into ambient, design and social factors. Ambient factors refer to the non-visual elements of a space that tend to impact the consumer's subconscious, such as temperature, music, and lighting. Design factors are the stimuli that represent the visual elements of a space that tend to exist more at the forefront of a consumers' awareness, such as color, layout and architectural elements. Social factors involve the presence of employees and customers in the environment. Researchers have found that physical environment induces two types of internal states for an individual: affective and cognitive [Zeithaml, 1988; Mehrabian and Russell, 1974]. Each type of evaluation impacts a consumer's shopping behavior in a different way. According to the S.O.R. framework, approach avoidance behaviors are the actions resulting from individuals' internal states. Mehrabian and Russell [1974] suggest that approach behaviors include physical approach, work performance, exploration, and social interaction. Using the S.O.R. framework, Figure 1 summarizes the components and constructs of each stage in our study. More specifically the three dimensions of S.O.R. framework are: (a) stimuli that consist of ambient, design, social and economic cues, (b) organism that consist of cognition and emotions, (c) response consist of satisfaction and dissatisfaction. We approach these three parameters by using the personal the situational moderators, such as age, gender, role and year of study. 


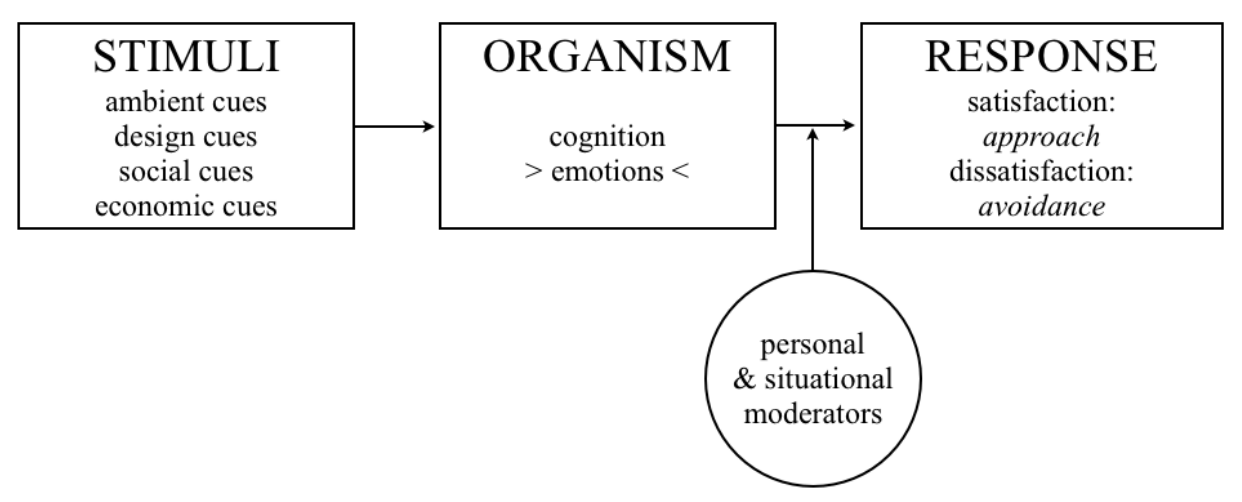

Figure 1: the S.O.R. model as adapted in our study

\section{Results}

The final sample consists of 950 library users from the age of 18 to 55, including women and men at almost equal percentages (50.3\% and $49.7 \%$ respectively). The majority of them were graduate students $(69.5 \%$ of the sample), with $22.9 \%$ of the sample being postgraduate students, $4.7 \%$ academic staff and $2.8 \%$ external users. The average age of the sample library users is 24 years old and the mean of library visits is 8.5 times monthly. Participants use electronic services with mean value 6.83 times monthly. Figure 2 shows the percentage of usage of traditional and electronic services by library users. All the electronic services are in blue and all the traditional services - those served in the physical are in red.

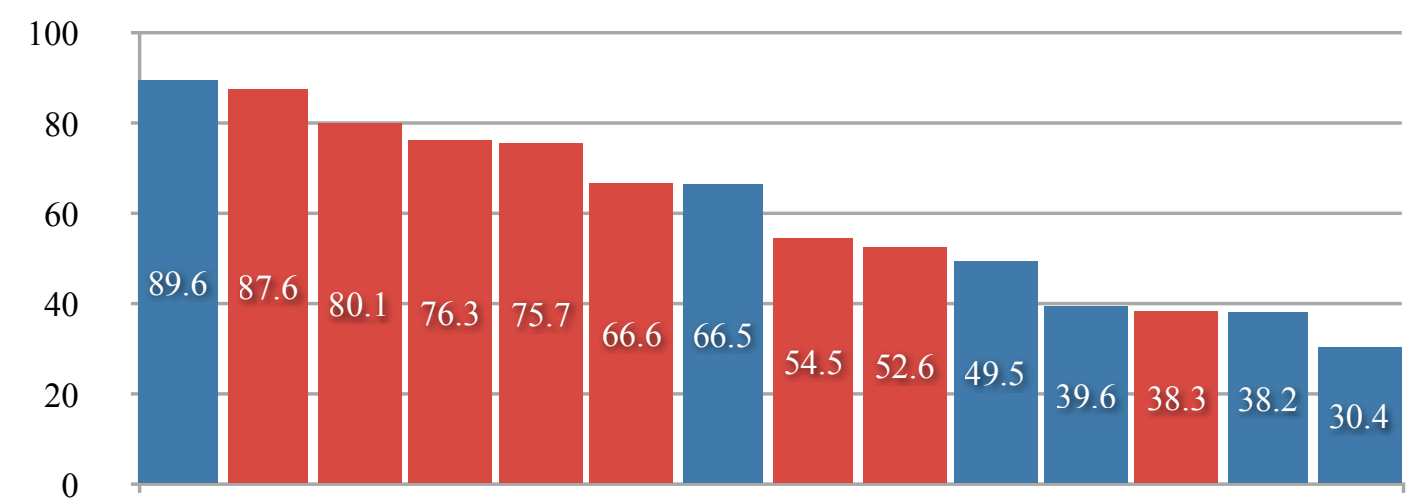

Blue: electronic Service / Red: physical service

\begin{tabular}{l|lll} 
Website & Reading rooms & Circulation & Printed Books \\
User Support & PC Lab & Web OPAC & OPAC Workstations \\
Copying & E-Journals & E-Learning system & Printed Journals \\
Databases & E-Books & &
\end{tabular}

Figure 2: Usage percentages per service (legend reads from left to right, shows only up to $30 \%$ )

Our results indicate that the web site of each academic library has the highest percentage of usage with $89.5 \%$ of the total sample. The second bar highlights the preference towards reading rooms, a traditional service, with a percentage rate of 87.5. The diagram also shows that traditional services are used more often by the 
Greek users. Circulation, Printed Books, User Support show also high percentages of usage. On the other side, the Interlibrary Loan, user education, audiovisual laboratory and European Documentation Center services have low scores. In overall, the mean percentage of usage for the traditional library services is $46.3 \%$ of the total sample. Low usage percentages are observed by Data bases $(38,2 \%)$ and e-books $(30.4 \%)$ from the electronic services and printed journals (38.3\%) from the traditional services.

Users responses are stimulated by specific cues, which consist of ambience, design, social and economic cues. For the ambience cues, light scores the highest with a mean value of 3.86, while conditioning and sound scores high too. Signage, a design cue, in every library scores also quite high (3.66). For the economic cues, fines score high (3.22), whereas in the social cues score the highest of all are the willingness (4.00), the kindness (3.98) and the knowledge (3.94) of library staff.

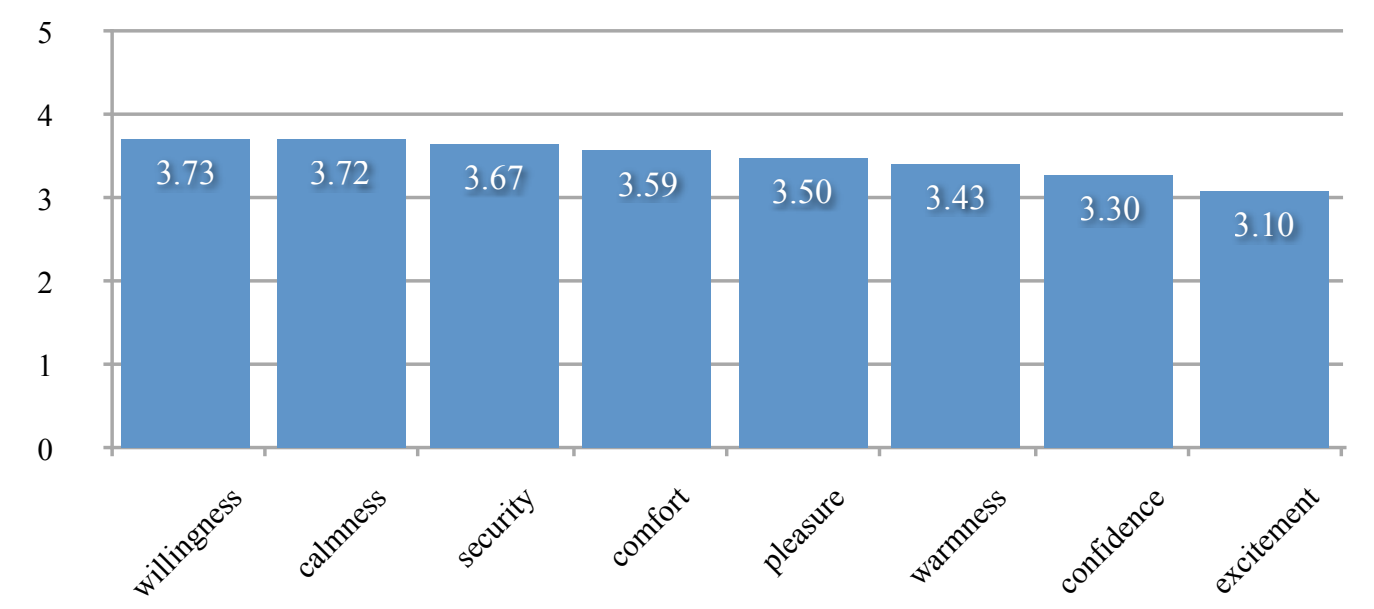

Figure 3: the S.O.R. model as adapted in our study

Consequently, the dimension of 'Organism' consists of the emotions that the library causes to its users. The results of our study show that the users are very willing to come to the library and that within their context the feel calm. All emotion responses were above the average with the users stating that the don't feel very excited when they come to libraries.

We found that there is a balance between the emotions of male and female users. Users of both genders stated that they are willing to visit the library and that they feel calm when they visit it with mean value above 3.70 . These scores were followed by quite high scores - in both genders - on the feelings of security (3.68) and comfort (3.58). We also found that users from the age of 28 to 47 years old are those that have the most positive feelings about the library services and the environment, whereas the younger or older users than this age seem to have less strong feelings. The highest feeling for new users is willingness $(3,72)$ and for the older users - from the age 48 to 55 - is security (3.90). Willingness has also received high scores especially from users aged between 38 to 47 (4.00). The scores of excitement are the lowest ones - between 3.1 and 3.3 - for all age ranges.

Faculty members show the top rating in all emotions. They feel safe (4.02) in the library, probably because they are familiar with the library environment. The external users express high levels of excitement (3.59), maybe because the academic libraries 
are not part of their own reality, as well as because they use the library services by consciously. Undergraduate students seem to be less emotionally attached to the library, especially.

The year of study gives us very different results about the emotions of our participants. There were found differences in safety, willingness and confidence. First to third year students are more willing to visit the library (an aggregated 3.77) and feel more safe (an aggregated 3.78) in the library than the older students. Students who are in fourth of the fifth year are willing too (3.78 and 3.7 respectively), while students above the sixth year of study feel more comfortable (3.88). It was quite surprising to find that students that are at the end of their studies have high emotions of excitement about the library (3.8 for students at their eight year of study).

Table 2: Factor analysis groupings

\begin{tabular}{|c|c|c|c|c|c|c|c|}
\hline \multicolumn{2}{|c|}{ Factor 1 (Social) } & \multicolumn{2}{|c|}{ Factor 4 (ambient) } & \multicolumn{2}{|c|}{ Factor 5 (design) } & \multicolumn{2}{|c|}{ Factor 11 (economic) } \\
\hline Variables & Loadings & Variables & Loadings & Variables & Loadings & Variables & Loadings \\
\hline $\begin{array}{l}\text { Attentive } \\
\text { staff }\end{array}$ & ,795 & \begin{tabular}{|c|} 
Quiet space \\
for \\
individual \\
study
\end{tabular} & ,765 & Colors &, 745 & $\begin{array}{l}\text { Fines and } \\
\text { fees }\end{array}$ & ,940 \\
\hline $\begin{array}{c}\text { Capacity of } \\
\text { staff }\end{array}$ & ,764 & $\begin{array}{c}\text { Space for } \\
\text { group study }\end{array}$ & ,764 & $\begin{array}{c}\text { Heating, } \\
\text { ventilation, } \\
\text { etc }\end{array}$ &, 723 & $\begin{array}{c}\text { Cost for } \\
\text { photocopies }\end{array}$ & ,835 \\
\hline Caring staff &, 751 & $\begin{array}{c}\text { Perception } \\
\text { of gateway } \\
\text { for study \& } \\
\text { learning }\end{array}$ & ,724 & Smells & ,689 & $\begin{array}{l}\text { Cost for } \\
\text { printing }\end{array}$ & ,602 \\
\hline $\begin{array}{l}\text { Ready and } \\
\text { responsive } \\
\text { staff }\end{array}$ &, 725 & $\begin{array}{l}\text { Inspiring } \\
\text { space }\end{array}$ & ,698 & $\begin{array}{l}\text { Design of } \\
\text { the library }\end{array}$ & ,637 & & \\
\hline $\begin{array}{c}\text { Understandi } \\
\text { ng staff }\end{array}$ &, 720 & $\begin{array}{c}\text { Comfortable } \\
\text { and inviting } \\
\text { location }\end{array}$ & ,611 & Lighting & ,390 & & \\
\hline $\begin{array}{l}\text { Courteous } \\
\text { staff }\end{array}$ & ,699 & $\begin{array}{c}\text { Building of } \\
\text { library }\end{array}$ & ,560 & & & & \\
\hline Willing staff & 684 & & & & & & \\
\hline $\begin{array}{c}\text { Knowledga } \\
\text { ble staff }\end{array}$ & 653 & & & & & & \\
\hline $\begin{array}{c}\text { Staff } \\
\text { instilling } \\
\text { confidence }\end{array}$ & ,575 & & & & & & \\
\hline
\end{tabular}

'Response' consists of user's satisfaction and answers to whether these emotions are translated to approval and approach or disapproval and avoidance of the services. In our survey it was found that the majority of users are very satisfied at a percentage of $49 \%$. There is no difference between men and women about the percentage of 
satisfaction. Both genders are very satisfied about library services ay the percentage of $49 \%$. Students at the $3^{\text {rd }}$ year of their studies have the highest satisfaction and at the last year of their studies has the lowest.

Factor analysis confirmed the four theoretical groupings of cues. The first - and the most important - factor of 'Stimuli' is the social cues, which groups all the characteristics of the library staff. In this grouping, the highest factor loading is the opinion on the attentive library staff $(0.795)$ The second factor is the ambient cues that consists mainly of the physical aspects of the library and the highest factor loading is concentrated on the variable "Quiet space for individual study" (0.765). The third factor is the design cue with the top variable "colors of the library" $(0.745)$ and the last one is the economic cue. The "economic fine" has the highest factor loading of that cue (0.940).

No significant differences were found between the various status categories with the exception of safety $(p>.01)$. In academic years, differences were found to be statistically significant for safety $(p>.01)$, willingness $(p>.05)$ and confidence $(p>.01)$. Homogeneity of variations, a test to show if the variations were similar, was found mostly insignificant, showing that they were mostly homogeneous. We also performed correlation analysis (Pearson) the age and the emotions have a weakly positive correlation (0.042), while the correlation of the year of study and the emotions is a weakly negative one (-0.084). Correlation is significant at the 0.01 level $(p>.01)$.

\section{Discussion}

Library users are in overall satisfied by the personnel behavior and productivity, but they also believe that there are margins for further improvement of its knowledge, while they think that the cost of services should be revised and echo the current situation. Library users in Greece prefer using physical services in comparison to the electronic ones. This might imply that they are not well informed about electronic services or that electronic services are not well integrated in the curricula. Users also seem to prefer features that have immediate effect to their daily interaction. In their view an ideal library is a fathoming environment that facilitates reading and cooperation with friendly and willing personnel and affordable fees and fine rates.

Our study's impetus was internal. It was an arduous task to collect the data in a very methodological sound way. This was achieved with the assistance of liaison librarians in the surveyed libraries that helped us complete the survey. This reflects that with a careful planning one can achieve collecting user based data in a representative fashion.

Our future work is to examine whether these cues interact together and how and if they are drivers to social or systemic interactions. For instance, if there are fines and library users have proven inability of fines payment, what is the model of interaction that helps the resolution of this challenge in a mutually benefit way?

\section{Conclusions}

The study applied the Stimulus-Organism-Response behavioral framework and used a gap analysis scale to measure the opinion of the users on the criteria categories. It is a 
quantitative survey and as such it provides the broad view of the current situation in the country. It focused on important drivers of the expression of affective relationships and its findings can be useful to library administrators as it highlights the effects of economic crisis on key areas of library operation. The findings of the study can assist library administrators to define the range of interventions and to prioritize them in a period of limited resources. In general academic library users in Greece consider them to be spaces that facilitate pleasant reading and studying, as well as efficient collaborative work.

\section{References}

Baker, J. (1987), "The role of environment in marketing services: the consumer perspective". In John A. Czepeil et al. (eds.) The Services Challenge: Integrating for Competitive Advantage, Chicago, IL: American Marketing Association.

Kim, J. and Lennon, S.J., (2013). "Effects of reputation and website quality on online consumers' emotion, perceived risk and purchase intention: Based on the stimulusorganism-response model". Journal of Research in Interactive Marketing, Vol 7 No 1, pp.33-56.

Kyrillidou, M. (2006), "Library assessment: why today and not tomorrow?" In Moreleli Cacouris, ed. Library assessment, Thessaloniki: Association of Research Libraries.

Markin, R. J., Lillis C.M. and Narayana C.L. (1976), "Social psychological significance of store space". Journal of Retailing Vol 52 No 1, pp. 43-54.

Mehrabian, A. and Russell, J.A. (1974). An approach to environmental psychology, Cambridge, MA: MIT Press.

Powell, R.R. (2006), "Evaluation research: an overview". Library Trends Vol 55 No 1, pp.102-120.

Zeithaml, V. A. (1984), "Issues in conceptualizing and measuring consumer response to price". In Thomas C. Kinneareds (ed.) Advances in Consumer Research, XXI. Provo, UT: Association for Consumer Research, pp. 612-616. 